\title{
YOUTH EMPOWERMENT AND CONTRACEPTIVE USE IN NEPAL
}

\section{Bidhya Shrestha*}

Contraceptive choices have an enormous impactonhealth, schooling and employment prospects. Access to full range of contraceptive method is vital for ensuring the health of youth.This study examined the association between youth empowerment in the domestic sphere and contraceptive use among currently married female youth in Nepal using the data of Nepal Demographic Health Survey, 2011. A sample of 2,553 currently married women of reproductive age 15-24 were chosen for this study. Bivariate analysis with cross tabulation and chi-square test were used to examine the association betweeneach independent and dependent variables. Logistic regression model was employed for examining the effect of each independent variable as well as control variable on dependent variable. Result showed that the effect of youth empowerment remains statistically significant and has influence on their use of contraceptives, even after adding the control variables into the model. Youth who are empowered they use contraceptive about 2 times higher than those who are not empowered. Influence of some selected socio-economic and demographic variables on contraceptive are also examined. The study shows that the presence of son at home on contraceptive use is strongly associated ( $\mathrm{OR}=4.58)$. Thus youth empowerment is necessary to increase contraceptive use.

Keyword: Youth, empowerment and contraceptive use.

\section{INTRODUCTION}

Every individual has the right to have children, if and when they want (UNFPA, 1995). Many individuals, however, cannot implement this right in part because of community, familial, and religious impediments and in part because of obstacles they face in accessing and using family planning (FP) services. Access to safe and voluntary family planning is a human right. Freeing women from involuntary reproduction was one of the main inspirations for family-planning pioneers 100 years ago and remains just as relevant today. The reproductive revolution-the shift from six births, of whom several might die, to around two births, nearly all of whom surviverepresents the most important step towards achievement of gender equality by boosting women's opportunities for non-domestic activities. In most developing countries, for instance, women's participation in the labour force has increased as fertility has fallen (UN, 1995).

Young people's reproductive choices have an enormous impact ontheir health, schooling and employment prospects, as well as their overall transition to adulthood. One out of every six women of reproductive age in less developed countries is age 15-19. This group of 250 million young women is projected to grow to 300 million by 2060 (United Nations, 2015).Many women still start having sex, marry, and start having children before they turn 20. By age 19, half of young women in developing countries have had sex, one in three is married, and one in four has given birth. Roughly half the 21 million pregnancies of adolescent women that occur annually are

* Ms. Shrestha is Lecturer at Central Department of Population Studies (CDPS), Tribhuvan University, Kirtipur, Kathmandu, Nepal. 
unintended; a majority end in abortion. This high proportion of unintended pregnancies is unsurprising, given that only 40 percent of adolescent women in need of family planning use a modern method, 9 percent a traditional method, and 51 percent no method (Darroch, Woog, Bankole, \& Ashfor, 2016).Meeting their family planning needs is a crucial challenge for all countries.

In spite of women's commonality regarding the basic problem there are many divisions among women in the Nepal. Urban women are divided from rural women; unemployed are divided from employed women; uneducated women are divided from educated women. It is widely thought that women have more say in household decisions are more likely to have more power and influence in the family, and thus are able to influence reproductive decisions such as contraception use (Govindasamy \& Malhotra, 1996).

Empowerment may be key factor for using contraception. Women's empowerment process has proved to be a central factor in the achievement of many demographic and social desirable goals. Different literaturealso shows that woman's empowerment matters in contraceptive use (Kishor, 1995; Afifi, Riyami, \& Mabry, 2004). Adoption of the most effective methods of contraceptive requires individual decision-making and negotiation with contraceptive providers.

It is sometimes assumed that once women are married, barriers to contraception will be use removed. However, in some places, young married women still face barriers to contraceptive use. One way to look at this is by examining the ratio of unmet need for contraception among young married women (15-24) compared to all married women in Nepal. According to MoHP; New ERA and Macro International Inc. (2012) about 4 in 10 youth have unmet need for family planning which was lower in other age group. Most young women having an unmet need for contraception also wish to space births rather than limit family size.Nepal has a young population. Although the median age at first marriage has been rising, half of women are married by age 18. Nepali youth women have the lowest rates of contraceptive use and highest rates of unmet need. Much of the gap between women's total and wanted fertility rates in the Nepal can be attributed to low contraceptive use and high levels of unmet need for contraception. This failure can have grave consequences for individual young women, their children, families, and societies. Poor women, rural women and young women are particularly likely to experience unintended pregnancy and to seek abortion under unsafe conditions.

Sex, marriage, and childbearing too early can cut short educational and social opportunities for young women, and have a long-term negative impact on their job and income prospects. Not meeting their family planning needs can also harm their health and that of their children and families. Meeting the family planning needs of this age group(15-24 years) is essential.The purpose of this study therefore is to examine the relationship betweenempowerment in domestic sphere and contraceptive use among married youth women. It has focusedon currently married youth women status as in Nepal the majority of births occur within the marriage.

\section{DATA AND METHODS}

The data used in this study come from the 2011 Nepal Demographic and Health Survey (NDHS 2011). The NDHS 2011 covers a representative sample of 9608 currently married women in the age group of 15-49 years. For the purpose of this paper, only 2553 currently marriedwomen aged 15-24 are included in the analysis. According to UN definition these groups are youth and same definition is followed in this study. 
The outcome variable was current use of contraceptives. In this study the independent variable, women empowerment, is measured by women's participation in household decision making, The variable, women's participation in household decision making, comes from the question "Who in your family makes decisions about (1) healthcare for yourself, (2) large household purchases, (3) and (4) visits to family and/or relatives?”

The possible answers are 1) respondent alone, 2) respondent and husband/partner jointly, 3) Respondents and other person 4) husband/partner alone, 5) someone else 6) other. If the women indicates that she had a say in a decision, whether by herself or jointly she received a score of 1 . Based on the responses to these three questions, responses are first dichotomized.The value of 1 is assigned if the response was 1,2 , or 3 that is, involvement of the respondent in household decision, or else 0 , for no involvement of the respondent. The other independent variables included in this study were demographic and socioeconomic variables such as age, sex composition of children, caste/ethnicity, education, working status, media exposure, wealth index of households and place of residence. Logistic regression has been used to establish the association between the individual indices and contraceptive use controlling for key background characteristics. Data is presented for both unadjusted and adjusted odds ratio at 95 percent confidence intervals.

\section{RESULTS}

Result in Table 1 indicates the levels of contraceptive use by selected background of currently married youth female respondents. Data shows that about 3 in 4 respondents are not using contraceptives.Overall, the contraceptive prevalence rate (CPR) in the study was about 25 percent. Table 1 reveals that current use of any contraceptive method was significant $(\mathrm{P}<0.001)$.Contraceptive use was higher among 20-24 years youth, Janajati, who had both daughter(s) and sons(s), the youth with higher level of education, who are working on paid, who heard FP massages, among the urban residents and among rich household. Similarly youth who can refuse sex are using more contraceptive methods than who reported that they cannot refuse sex.Data further says that there are still more youth who are not using contraception in one side and otherside they cannot refuse sex when their partner forces her. As a result there are chances for higher incidence of unwanted pregnancy and early childbearing. The CPR was higher among those who are empowered in household compared to those who are not empowered(34.6\% vs. 21.2\%).

Table 1: Percentage distribution of currently married youth according to contraceptive use by background characteristics

\begin{tabular}{|l|r|r|r|}
\hline Background Characteristics & Non users & \multicolumn{1}{l|}{ Users } & \multicolumn{1}{l|}{ r } \\
\hline Age group*** & & & \\
15-19 & 82.4 & 17.6 & 792 \\
20-24 & 70.5 & 29.5 & 1,761 \\
Caste/ethnicity & & & \\
Brahmin/Chhetri & 73.2 & 26.8 & 736 \\
Dalit & 80.2 & 19.8 & 483 \\
Janajati & 69.8 & 30.2 & 943 \\
Other & 79.0 & 21.0 & 392 \\
Place of residence*** & & & \\
Urban & 60.4 & 39.6 & 253 \\
Rural & 75.7 & 24.3 & 2,300 \\
\hline
\end{tabular}


Table 1 continued

\begin{tabular}{|l|r|r|r|}
\hline Sex composition of living children*** & 88.4 & 11.6 & 861 \\
None & 64.2 & 35.8 & 696 \\
Only son & 71.9 & 28.1 & 631 \\
Only daughter & 63.8 & 36.2 & 366 \\
Both & & & \\
Educational status*** & 77.5 & 22.5 & 684 \\
No education & 76.0 & 24.0 & 588 \\
Primary & 71.5 & 28.5 & 1,281 \\
Secondary and above & & & \\
\hline Working status*** & 77.6 & 22.4 & 1,317 \\
Currently not working & 74.3 & 25.7 & 878 \\
Working but not paid & 61.4 & 38.6 & 358 \\
Working but paid & & & \\
Family planning massages*** & 79.0 & 21.0 & 940 \\
Did not hear/listen FP massage in past few months & 71.3 & 28.7 & 1,612 \\
Heard FP massages on radio, TV or newspaper in past few & & & \\
months & & & \\
Wealth index*** & 77.6 & 22.4 & 976 \\
Poor & 77.0 & 23.0 & 623 \\
Middle & 68.8 & 31.2 & 955 \\
Rich & & & \\
Can refuse sex*** & 84.1 & 15.9 & 189 \\
No & 73.4 & 26.6 & 2,364 \\
Yes & & & \\
Women's empowerment*** & 78.8 & 21.2 & 1,666 \\
Not empowered & 65.4 & 34.6 & 886 \\
Empowered & 74.2 & 25.8 & 2,553 \\
\hline Total & & \\
\hline
\end{tabular}

***Significant at $p<.0 .001$.

Table 2 shows the results of logistic regression analysis of contraceptive use and contraceptive use among currently married youth women by socioeconomic characteristics and overall empowerment index. In model I the result is only for the women empowerment and contraceptive use. In model II adjusted OR controlling the background variable that predicts contraceptive use. The women who were empowered to take household decision had 1.96 times higher odds to use contraceptive compared to those who had no empowered. Even after controlling background variable, the odds of using contraceptive using remained significant with $1.44 \mathrm{OR}$. The odds of any contraceptive use was higher among youth who had both daughter(s) and son(s), youth with higher education, urban residents, who work as a paid worker, who had heard family planning massages, who can refuse sex and who are from rich household. 
Table 2:Adjusted and unadjusted odds ratio for youth empowerment and contraceptive use

\begin{tabular}{|c|c|c|}
\hline Independent variables & $\begin{array}{l}\text { Contraceptive use } \\
\text { Model I OR (95\% } \\
\text { CI) }\end{array}$ & $\begin{array}{l}\text { Contraceptive use } \\
\text { Model II OR (95\% } \\
\text { CI) }\end{array}$ \\
\hline $\begin{array}{l}\text { Women's empowerment } \\
\text { Not empowered (ref.) } \\
\text { Empowered } \\
\text { Age group } \\
\text { 15-19(ref.) } \\
\text { 20-24 } \\
\text { Caste/ethnicity } \\
\text { Brahmin/Chhetri (ref.) } \\
\text { Dalit } \\
\text { Janajati } \\
\text { Other } \\
\text { Place of residence } \\
\text { Urban (ref.) } \\
\text { Rural } \\
\text { Sex composition of living children } \\
\text { None (ref.) } \\
\text { Only son } \\
\text { Only daughter } \\
\text { Both }\end{array}$ & $\begin{array}{r}1.00^{* * *} \\
1.96(1.64-2.35)\end{array}$ & $\begin{array}{r}1.00 * * * \\
1.44(1.18-1.76) \\
1.00 \\
1.01(0.832-1.34) \\
1.00 \\
0.85(0.62-1.16) \\
1.23(0.97-1.55) \\
0.98(0.69-1.40 \\
1.00 \\
0.503(0.37-0.68) \\
\\
1.00 * * * \\
4.58(3.46-6.01) \\
3.12(2.34-4.16) \\
5.37(3.83-7.52)\end{array}$ \\
\hline $\begin{array}{l}\text { Educational status } \\
\text { No education (ref.) } \\
\text { Primary } \\
\text { Secondary and above } \\
\text { Working status(ref.) } \\
\text { Currently not working } \\
\text { Working but not paid } \\
\text { Working but paid } \\
\text { Family planning massages } \\
\text { Did not hear/listen FP massage in past few (ref.) } \\
\text { months } \\
\text { Heard FP massages on radio, TV or newspaper in past } \\
\text { few months }\end{array}$ & & $\begin{array}{r}1.00 \\
0.98(0.73-1.30) \\
1.17(0.88-1.548) \\
\\
1.00 \\
1.38(1.09-1.76) \\
1.97(1.49-2.60) \\
1.00 \\
1.32(1.05-1.65)\end{array}$ \\
\hline $\begin{array}{l}\text { Wealth index } \\
\text { Poor (ref.) } \\
\text { Middle } \\
\text { Rich } \\
\text { Can refuse sex(ref.) } \\
\text { No } \\
\text { Yes }\end{array}$ & & $\begin{array}{r}1.00 \\
1.17(0.90-1.53) \\
1.39(0.91-2.13)\end{array}$ \\
\hline $\begin{array}{l}\text {-2 Log likelihood } \\
\text { Cox \& Snell R Square }\end{array}$ & $\begin{array}{r}2864.2 \\
0.020\end{array}$ & $\begin{array}{r}2619.2 \\
0.110\end{array}$ \\
\hline
\end{tabular}

***Significant at $p<0.001$. 


\section{DISCUSSION}

Youth (ages 15-24) population continues to grow rapidly, particularly in low and middle-income nations. Their belief and decisions about family planning are critical to their sexual and reproductive health and rights. Too often, they face obstacle that limit their access to modern contraceptive methods of their choice. They experience less informed choice. These truths highlight the pressing need to improve the sexual and reproductive health of young people. Increase investment in contraceptive method and reproductive health allow them to implement their decision to have smaller families and open the window of opportunity for the demographic dividend (Aspen Global Health and Development, 2011). In this regard this study has also tried to investigate whether youth empowerment (measured by final say on own healthcare, large household purchases and visit to the relatives) matters in contraceptive use or not in Nepal. The study found that women empowerment is an important predictor of contraceptive use. Study results indicated that use of contraceptives is high among youth who are empowered or have a higher decision-making competency.

The results of the study further indicated that, sex composition of living children at home as a determinant to use contraception. Youth having both son and daughter at home are more likely to use contraceptives as compared to their other counterparts. Possible explanation to this observation might be that the youth may be highly motivated to use contraceptives as a societal expectation, that is, son preference.

Again, the study revealed that educated women were generally more likely to usecontraceptives than youth with no education. This implies thateducated youth possibly owing to their knowledgebase in contraceptives are probableto undertake better assessment thereby forming a positive attitude toward contraceptivesthereby transforming into higher usage of contraceptives. As argued by the theoryof planned behaviour, individuals will engage in any act upon thoughtfully reflecting onthe positive outcomes of the intended behaviour (Fishbein and Ajzen, 2010). The results also confirm the findings that youth engaged in paid job are more likely to use contraception than their counterparts. Therefore youth working in the paid job, possibly due to fear of losing their jobs due to pregnancy would rationally choose to use contraceptives in order to secure their jobs. This results also supported by Gage (1995), that confirms the women's economic power widens their contraceptive options as a result they use contraceptive.

Furthermore this study also revealed alarming results about the youth female power to refuse sex when her husband/partner asks. Data shows that majority (84.1\%) of the women who cannot refuse sex and are also not using any contraceptive methods. It indicates these portions of the youth are more vulnerable to have unwanted pregnancy. However, sex refusal among youth has also been widely used as part of measuring sexual empowerment in the literature(Upadhyay and Karasek,2012). Larger portionof youths, who can refuse sex are using contraceptive than their counterparts. Thus youths should be empowered to use contraceptive and their reproductive rights. So that it decreases unwanted pregnancy and risk of STDs.

\section{CONCLUSION}

Youth are the agents of change. Empowering them may solve the today's challenges and will also help solve tomorrow's problems. The result of this study has also proved that empowerment is 
significant predictor of contraceptive use. Youth empowerment is so really necessary. Those who are not empowered or thosewho cannot refuse sex and does not using contraceptive are much more prone to unwanted pregnancy, unsafe abortion and STDs. The higher the degree of women who can refuse for sex,particularly when she is either not in the mood or the husband/sexual partner does notagreeto use contraceptive, the more empowered they are to prevent from unwanted pregnancy or possibilities of health effect.The result is that they can use their time for achieving higher education and uplifting their overall development.Addressing to this issue, reproductive empowerment for youth is therefore necessary in terms of contraceptive use and national development as well.

\section{Acknowledgement}

The authors thank MEASURE DHS for providing access to the data. The author would also like to thank the reviewer of this paper for his valuable suggestions in this paper.

\section{REFERENCES}

Afifi, M., Al-Riyami, A., \& Mabry R. (2004).Women’s autonomy, education and employment in Oman and their influence on contraceptive use.Reproductive Health Matters, 12(23), 144-54.

Aspen Global Health and Development. (2011). Family planning promotes the demographic dividend, policy brief.Retrieved from https://assets.aspeninstitute.org/.../Demographic\%20Dividend\% 20Policy\%20Brief\%5B.

Darroch, J., Woog, V.,Bankole, A.,\&Ashford, L.S. (2016). Adding it up: Costs and benefits of meeting the contraceptive needs of adolescents. New York: Guttmacher Institute.

Fishbein, M.,\& Ajzen, I. (2010) Predicting and changing behaviour: The reasoned action approach. New York: Psychology Press.

Gage, A.J. (1995). Women's socioeconomic position and contraceptive behaviour in Togo.Studies in Family Planning, 26(5), 264-277.Retrieved from www.jstor.org on19/01/2010.

Govindasamy, P., \&Malhotra, A. (1996).Women’s positions and family planning in Egypt.Studies in Family Planning, 27(6), 328-40.

Kishor, S. (1995). Autonomy and Egyptian women: Findings from the 1988 Egyptian demographic and health surveys. Demographic and health surveys occasional paper 2. Calverton, Maryland: Macro International Inc.

Ministry of Health and Population (MoHP)[Nepal], New ERA, \& Macro International Inc. (2012). Nepal demographic and health survey 2011.Kathmandu, Nepal: MoHP, New ERA, \& Macro International Inc.

United Nations (UN). (2015). Trends in contraceptive use worldwide 2015 (ST/ESA/SER.A/349). New York: United Nations. 
(1995).The world's women 1995: Trends and statistics. Social statistics and indicators, Series K, No.12. New York: United Nations.

United Nations Population Fund (UNFPA). (1995).Report of the International Conference on Population and Development. New York: UNFPA.

Upadhyay, U.D.,\& Karasek, D. (2012). Women's empowerment and ideal family size: An examination of DHS empowerment measures in Sub-Saharan Africa. International Perspective on Sexual and Reproductive Health,38(2),78-89. 